\title{
Narrativas \\ autobiográficas, memoria y mitos: una aproximación a la acción social
}

\author{
Alicia Lindón \\ El Colegio Mexiquense
}

La realidad no existe, ella es construida. Los materiales utilizados son las palabras, las imágenes de las cosas y de las imágenes,

las imágenes de las imágenes de las cosas.

Didier Martin y Philippe Royer-Rastoll

En los últimos años las ciencias sociales han vuelto crecientemente su mirada hacia el estudio de los valores, las creencias, las ideas, el ethos, ${ }^{1}$ el conocimiento de sentido común u ordinario que trasciende a los individuos, pero que está presente en ellos y que resulta decisivo en la comprensión del otro, y así, en la construcción social del mundo. Todo esto es lo que de alguna manera esboza el campo de la subjetividad. Posiblemente, este giro de las ciencias sociales se relaciona con la complejidad que muestran las sociedades contemporáneas, los nuevos sujetos emergentes, las formas actuales de construir los vínculos sociales; así mismo, no podemos dejar de reconocer que también se asocia con lo

1 "Los aspectos morales (y estéticos) de una determinada cultura, los elementos de evaluación, han sido generalmente resumidos bajo el término ethos, en tanto que los aspectos cognitivos y existenciales se han designado con la expresión de 'cosmovisión' (visión del mundo). El ethos de un pueblo es el tono, el carácter y la calidad de vida, su estilo moral y estético, la disposición de su ánimo; se trata de la actitud subyacente que un pueblo tiene ante sí mismo y ante el mundo que la vida refleja”. Clifford Geertz, $\mathrm{La}$ interpretación de las culturas, Barcelona, Gedisa, col. Antropología, 1996, p. 118.

Economía, Sociedad y Territorio, vol. II, núm. 6, 1999, 295-310. 
poco que nos permiten conocer de esos fenómenos otros acercamientos, otrora fructíferos.

Para el sociólogo, para el investigador de la sociedad, la "subjetividad social es un ángulo particular desde el cual podemos pensar la realidad social"; ${ }^{2}$ pero para el individuo común, para "el ciudadano de la vida cotidiana", la subjetividad son los ojos con los cuales ve el mundo, lo interpreta, y en consecuencia, actúa en él. Nuestras acciones, nuestro obrar, no es independiente del pensar, del valorar, del imaginar, en suma, no es ajeno a un conjunto de procesos ligados a la conciencia. Por eso, creemos que este giro y desafío que enfrentan actualmente las ciencias sociales se asocia con la preocupación metodológica de constituir en objeto de estudio el vínculo entre "el hacer" banal y cotidiano y "el pensar" del individuo común.

De esta forma, una perspectiva de investigación de la realidad desde la subjetividad social implica ubicarnos en los valores, las creencias, ideas, imágenes, el ethos, el conocimiento ordinario, en vez de limitarnos a lo que se exterioriza de cada acción social, y en consecuencia crea la ilusión de que puede ser observable desde un pretendido lugar externo. Una mirada sociológica desde la subjetividad social nos lleva a conocer la realización de las acciones, las formas de obrar, dentro del entramado de sentidos y significados en el cual surge cada acción. Aunque la acción siempre emerge de manera espontánea, no se produce en un vacío de sentidos. ${ }^{3}$ Un mismo "obrar" puede tener distintos sentidos en diferentes contextos sociales, o incluso puede cambiar su sentido en un mismo contexto a través del tiempo. Ya dijo Weber que la acción social lleva consigo sentido; ahí está el desafío que con facilidad olvidamos, estudiar el sentido de la acción: "La actividad humana se orienta según un sentido que se trata de comprender para hacerla inteligible". ${ }^{4}$ Es por todo esto que para el sociólogo, la subjetividad social supone estudiar la acción social, con toda la complejidad de sentidos y significaciones que la acompañan.

A lo anterior se puede agregar otro desafío más específico: la exploración de los sentidos y los significados entretejidos en

\footnotetext{
${ }^{2}$ Hugo Zemelman (1997), "Sujetos y subjetividad en la construcción metodológica”, en Emma León y Hugo Zemelman (coords.), 1997, p. 21.

${ }^{3}$ Peter Berger y Thomas Luckmann, Modernidad, pluralismo y crisis de sentido. La orientación del hombre moderno, Barcelona, Paidós, Paidós Studio, 1997; y Thomas Luckmann, Teoría de la acción social, Barcelona, Paidós, 1996.

${ }^{4}$ Julien Freund, Sociología de Max Weber, Barcelona, Península, col. Homo Sociologicus, 1986, p. 85 .
} 
torno a cada acción particular que se haya decidido indagar, es un momento analítico. Otro momento es aquel en el que nos preguntarmos cómo se constituyen y reconstruyen esos contextos sociales de sentido en que los individuos desarrollan sus vidas, incorporándolos y, al mismo tiempo, modificándolos. ¿Cómo es que los individuos se apropian de ciertas ideas, ciertos patrones culturales, creencias, imágenes, de cierto conocimiento ordinario de su época y no de otro? Los procesos de socialización entendidos de manera amplia abren respuestas a estos interrogantes.

En síntesis, la comprensión de la sociedad desde la subjetividad social, trae consigo la consideración del punto de vista del individuo como agente social, además de la concepción de la realidad social como una construcción siempre inconclusa, y en términos metodológicos supone la revalorización de la interpretación. Desde esta perspectiva, la narrativa autobiográfica constituye un terreno fértil para el sociólogo, aunque con facetas difíciles de procesar en cuanto a metodología; y más aún por la enorme carga de prejuicios acerca de la supuesta verdad, que constantemente se interpone en el desarrollo de nuestro oficio, así como por los fantasmas de las concepciones de una realidad concreta y objetiva. $^{5}$

Desde este campo de la subjetividad social y la interpretación como la lectura que de ella hace el investigador, en este artículo primero incorporamos la cuestión metodológica de las narrativas autobiográficas como aproximación a la acción social y sus sentidos. Luego reflexionamos acerca del papel de la memoria en este tipo de narrativas, para terminar con la incorporación del mito como una forma de estructurar la narración a partir de un conocimiento colectivo que por su plasticidad puede asumir distintas formas, como son los mitos.

\section{Las narrativas autobiográficas}

Los relatos de vida o narrativas autobiográficas están anclados en la experiencia humana; son un recurso para reconstruir acciones sociales ya realizadas; no son la acción misma, sino una versión que el autor de la acción da posteriormente acerca de su propia acción pasada. Desde la posición de investigadores es importante

${ }^{5}$ Este tema es analizado detalladamente por Georges Benko en su artículo incluido en este mismo número. 
no olvidar que cuando un narrador nos cuenta fragmentos de su vida, de sus experiencias, estamos accediendo a una narrativa sobre ciertos procesos y relaciones sociales puestos en juego en una vida concreta, ${ }^{6}$ que nos invitan a interpretarla en varios planos. Mínimamente entran en juego dos niveles interpretativos. El primero y más evidente corresponde a las interpretaciones que realiza el investigador como escucha, como interlocutor, desde sus acervos de sentido común. Sin embargo, lo específico de este proceso interpretativo es que el investigador constantemente interpreta desde el sentido común, y vuelve a interpretar desde sus inquietudes e interrogantes teóricos. En otras palabras, de manera casi simultánea interpreta desde los constructos de primer grado y desde sus constructos científicos o de segundo grado, para recuperar la terminología schutziana. ${ }^{7}$

De lo anterior podemos concluir que uno de los rasgos que identifican a las narrativas o los relatos autobiográficos es, precisamente, su carácter "experiencial”. Se narran experiencias vividas por el narrador, recordadas, interpretadas, conectadas, en las que hay otros actores, pero siempre son experiencias de quien habla. Por esto en las narrativas autobiográficas el narrador construye un "personaje central" -un "héroe"- con sus propias experiencias. ${ }^{8}$

Otro de sus rasgos singulares, aunque pueda parecer evidente, es que son "relatos". Un relato supone que el narrador le da una estructura propia a su narración, construye una hilación peculiar. Si hubiera una semiestructuración construida por el investigador se perdería la estructura narrativa, que es la esencia del relato. Por ello, si se puede hablar de "la intención directiva del investigador" en el relato, sólo es en el inicio de la narración, cuando el entrevistador marca una pauta inicial para que el narrador empiece su propia construcción desde un ámbito de su vida. Lo directivo, en otros términos, atentaría contra la propia narración.

${ }^{6}$ Didier Vrancken, "Memoire de chapeliers: du récit à l'élaboration du mythe", Cahiers Internationaux de Sociologie, julio-diciembre, vol. 81, año 33, 1986, pp. 315324.

${ }^{7}$ Esto no quiere decir que la investigación empiece allí. Para que el investigador llegue a la situación de entrevista narrativa se requiere haber andado por un camino previo, en el cual evidentemente no se puede omitir la conocida "construcción del objeto de investigación", además, siempre provisoria.

${ }^{8}$ Carlos Piña, "Sobre la naturaleza del discurso autobiográfico", Argumentos, núm. 7, agosto, UAM-Xochimilco, 1989, pp. 131-160. 
El narrador construye un hilo conductor entre experiencias que ha vivido -sean lejanas o próximas en el tiempo- y que considera significativas socialmente, al tiempo que se "reconoce lealtad a sí mismo" por ese hilo conductor seguido. Esto supone que al escoger y articular las vivencias para narrarlas de manera comprensible a los otros, el narrador recurre a su memoria y también a un contexto sociocultural (que es parte de su conocimiento de sentido común) en el que esas experiencias toman sentido, conectando así acontecimientos y situaciones cotidianas. ${ }^{10}$ Por eso la estructura narrativa no puede ser impuesta por el investigador, no hay "una verdad" que tenga que aflorar en la entrevista autobiográfica, sólo habrá experiencias "escogidas" en la memoria, y conectadas entre sí narrativamente. ${ }^{11}$ Cuáles sean escogidas, dentro de lo infinito de cada instante vivido, dependerá de la selección del narrador, y no de una imposición externa a él.

Por último, nos parece necesario identificar un tercer rasgo característico de estas narraciones: son "significativas socialmente". La estructuración narrativa hace que lo experiencial pueda ser comprendido por "el otro" (el investigador). En otras palabras, se produce una "traducción" de lo íntimo ${ }^{12}$ de las experiencias vividas, a formas compartidas socialmente, por medio del lenguaje. Esa traducción ocurre por efecto de las estructuras narrativas que preexisten al individuo, aunque las ha incorporado y puede transformarlas mediante los procesos de formación y entrelazamiento de las ideas. Por ejemplo, para Ricœur las experiencias sólo pueden ser transmitidas por medio del lenguaje; el acto de colocar la experiencia en el lenguaje la hace perder lo individual y privado para transformarla en "singular". Así, el relato autobiográfico no sólo es de tipo experiencial, sino también significativo socialmente, ya que cada experiencia seleccionada ha sido traducida a un contexto sociocultural gracias al lenguaje.

La narración autobiográfica no es para indagar en la parte íntima de una vida, sino para acceder a un discurso construido en un contexto de significado, objetivado en el lenguaje. Se trata de

${ }^{9}$ Anthony Giddens, Modernidad e identidad del yo. El yo y la sociedad en la época contemporánea, Barcelona, Península, 1997, pp. 104-105.

${ }^{10}$ Franco Crespi, Acontecimiento y estructura. Por una teoría del cambio social, Buenos Aires, Nueva Visión, 1997, pp. 7-30.

${ }^{11}$ Siguiendo a Luckmann, antes que hablar de causalidad se opta por la idea de "conexiones".

${ }^{12}$ Lo "íntimo" no da cuenta de lo privado que no puede ser hablado, más bien expresa la vivencia tal como fue experimentada interiormente por el individuo, aun cuando sea una vivencia que no tenga nada de prohibido. Lo íntimo se refiere al "sólo yo sé lo que sentî”. 
un discurso construido sobre un conjunto de "saberes compartidos". En esta concepción de lo biográfico el individuo sólo cabe como expresión singular de lo social. ${ }^{13}$ Dicho sea de paso, esto también desmonta la falacia de la posible mentira, que sólo existe a partir de la individualidad de la vida concreta del narrador, pero no desde su singularidad social. Si el narrador inserta en su relato una vivencia que no ocurrió en su trayectoria, seguramente que esa experiencia era posible en el contexto sociocultural en el que se posicionó, que es la meta del investigador antes que la individualidad. Más aún, por haberla expresado verbalmente puede constituirse en un "motivo para" de una acción futura, podría servir para "planear" una acción futura.

Ubicados en este ángulo, comprendiendo la narrativa autobiográfica desde estos rasgos, resulta importante reflexionar sobre algunos procesos que entran en juego en esa instancia. En este tipo de circunstancias, nuestras cargas "objetivistas" tan apegadas al "aislamiento" (en el sentido experimental), casi siempre nos llevan a focalizarnos en el producto mismo, en este caso la narración, lo que se facilita aún más cuando la vemos como textos (desprendida del sujeto que la construyó), y tendemos a olvidar el contexto interaccional en que se produjo tal narración. Sin embargo, consideramos importante analizar un poco más detenidamente los procesos implicados en esa situación en la cual le solicitamos a un sujeto que hable de sí mismo, o más concretamente, acerca de algo de sí mismo, ${ }^{14}$ como una estrategia metodológica para aproximarnos a una sistema de significados sociales. Este tipo de reflexión es lo que nos permitirá adoptar la narrativa autobiográfica por razones diferentes a la simple moda, y también hará posible ubicarla en un lugar que no puede ser pensado desde cuestiones como "la mentira y la verdad".

\section{La teatralización y los juegos de la memoria en las narrativas autobiográficas}

La invitación a contar la propia vida o parte de ella desencadena en el entrevistado un patrón lingüístico concreto, aprendido des-

\footnotetext{
${ }^{13}$ Marie-Françoise Chanfrault-Duchet, "Le système interactionnel du récit de vie", Sociétés, mayo, 1988, pp. 26-31.

${ }^{14}$ Respecto a ese momento, consideramos que Chanfrault-Duchet es una de las autoras que ha realizado un análisis más detallado desde la perspectiva del sistema interaccional establecido entre el entrevistador y el entrevistado. Cf. idem.
} 
de la infancia, como es la narración. El niño aprende a relatar escuchando historias, cuentos, relatos. Sin embargo, también es importante recordar que esta invitación no sólo abre el patrón narrativo, sino que igualmente impulsa una cierta motivación estética, lo que no debe confundirse con presentar un relato "be1lo". Es en este último sentido de lo estético que los relatos de vida o narrativas autobiográficas, también pueden ser considerados productos literarios en los que se entreteje la ficción; ésta siempre se teje con base en algún criterio estético. Sin embargo, esa ficción da cuenta de la realidad social.

Si se considera lo anterior, es decir, el montaje estético de la narración, no es posible concebir al narrador como un testigo pasivo de los acontecimientos, como mero depositario de un saber que simplemente nos entrega; también es un actor capaz de actuar y construir un discurso sobre su sociedad y su vida dentro de esa sociedad. No podemos considerar al narrador como "un banco" de datos ${ }^{15}$ que se abre y emite la información que estamos buscando. El narrador hace un verdadero "montaje" cuando narra, se construye a sí mismo como el personaje central. Ese montaje no debería ser entendido desde una intención de "engaño", de manipulación, sino que puede ser comprendido en la perspectiva de que al narrar su vida el individuo la vuelve a pensar, incluso de manera amplia podríamos decir que deviene en sociólogo de su propia biografía, ya que busca establecer conexiones entre acontecimientos, construye secuencias de eventos con las que selecciona unos para incluirlos y excluye otros; incluso llega a veces a interrogarse a sí mismo acerca de las motivaciones que tuvieron sus propias acciones.

Ese acto de volver a pensar la propia historia, evidentemente es un proceso realizado desde el presente, aunque sabemos que es un presente en el que se ha sedimentado toda una biografía, que además es parte de una sociedad. Es un presente que siempre contiene al pasado. Así, el pasado es relatado con referencia a las condiciones actuales de la existencia, aunque también con relación a esquemas incorporados en otros momentos; ${ }^{16}$ por eso decimos que el narrador vuelve a pensar su biografía, vuelve a pensar lo ocurrido con relación a esquemas cognoscitivos incorporados con posterioridad a los eventos narrados, pero anteriores al presente. Esto es lo propio de la narrativa autobio-

${ }^{15}$ Marie-Françoise Chanfrault-Duchet, "¿Le récit de vie: donnée ou texte?”, $C \boldsymbol{a}$ hiers de Recherche Sociologique, vol. 5, núm. 2, otoño, Montreal, 1987, pp. 11-28.

${ }^{16}$ Didier Vrancken, 1986. 
gráfica y no tiene por qué considerarse como un rasgo indeseable o como una limitación de este enfoque. Antes bien, ahí reside su gran fecundidad para acercarnos a lo que Hugo Zemelman llama el "filo del presente" o el movimiento social, ese presente que todavía no ocurre pero que encuentra en ese nivel consciente dado por la narración, toda la potencialidad para concretarse en la próxima acción, en la acción que todavía no se ejecuta. ${ }^{17}$

Esas transformaciones, o menos aun, distorsiones, que sufre la acción social ya realizada cuando es puesta en el circuito del lenguaje, cuando es comunicada a otro, se pueden explicar desde varios ángulos que convergen entre sí. Como acabamos de ver, uno de estos ángulos es la concepción estética del montaje del relato, la teatralización. Otro tiene que ver con los procesos de la memoria; y aun podemos mencionar un tercer ángulo, que refiere a los procesos de socialización, mediante los cuales el individuo sigue siempre incorporando nuevo conocimiento ordinario con el que ve (interpreta) el mundo; así, los procesos de socialización se conectan con los mecanismos de la memoria. Por último tenemos un cuarto ángulo para comprender la distorsión entre la experiencia y su narración, que deriva de la construcción de la identidad de sí mismo efectuada por el narrador. Revisemos más detenidamente estos ángulos.

En cuanto a los procesos de la memorización y rememoración, las teorías de la memoria nos enseñan que las cosas que captamos sufren una modificación en el momento de retroceder a la memoria, en el proceso mismo de su almacenaje, pero también en el momento de reproducirlas como recuerdos. Esto no le resta valor a nuestro acercamiento, sino más bien muestra los vericuetos de la construcción social de la realidad: "La memoria está hecha de pasado perdido y encontrado para permitir que el futuro ocurra. El recuerdo está del lado de lo que puede ocurrir". ${ }^{18}$

La otra dimensión no menos destacada es la transformación constante de cada individuo a través de su tiempo biográfi-

${ }^{17}$ Hugo Zemelman, "Sobre la importancia de las realidades que se ocultan", Tramas, Subjetividad y Procesos Sociales, núm. 6: Sujeto y Subjetividad, UAM-Xochimilco, 1994, pp. 9-20; Emma León y Hugo Zemelman, "Presentación", en Emma León y Hugo Zemelman (coords.), Subjetividad: umbrales del pensamiento social, col. Ciencias Sociales, Barcelona, Anthropos-CRIM-Coordinación de Humanidades, 1997, pp. 918; Hugo Zemelman, "Sujetos y subjetividad en la construcción metodológica", en Emma León y Hugo Zemelman (coords.), op. cit., p. 21.

${ }^{18}$ Robert Cabanes, "El enfoque biográfico en sociología”, Cuadernos del CIDS, serie II, núm. 1, julio, Bogotá, 1996, p. 65. 
co, cuestión que podemos plantear bajo la idea de Norbert Elias de que los individuos nunca están totalmente "terminados". ${ }^{19}$ En otras palabras, a lo largo de toda la vida seguimos sedimentando experiencias, que vienen a representar nuevos conocimientos de sentido común, y en consecuencia, siempre seguimos construyendo nuevos referentes con los cuales orientarnos en el mundo. Debido a esto último, las interpretaciones que hacemos en distintos momentos de nuestra vida respecto de una misma experiencia no tienen por qué ser iguales, ya que con el tiempo vamos incorporando más esquemas interpretativos.

Ambas cuestiones (las dinámicas de la memorización/rememoración y la socialización nunca acabada) tienen que ver con el tiempo; su esencia es temporal, y los relatos de vida se inscriben en el tiempo, dado que acuden sin cesar a la rememoración de imágenes y marcas del pasado, para traerlas al presente. Por esto, la transformación de la acción al ser narrada es algo propio del relato autobiográfico.

También señalamos que estas distorsiones de la experiencia se pueden entender con referencia a la construcción de la identidad. Estas distorsiones a veces han sido identificadas como procesos de "armonización retrospectiva" de la propia historia, que usualmente se explican por la necesidad de presentar una identidad unificada. ${ }^{20}$ Dicho en otros términos, ante las contradicciones que conforman la vida de cada individuo, aparece la necesidad de presentarse al otro como "único", lo que sólo puede resultar de esa reconstrucción de la identidad que se produce en la narración del "quién soy", ya que en el registro de las experiencias vividas es donde no somos "únicos". ${ }^{21}$ Por ende, el individuo busca construirse a sí mismo sin contradicciones, pero lo relevante es que cada individuo casi siempre es capaz de construir más de una identidad de sí mismo de tipo monolítico, por toda la heterogeneidad que lleva consigo, y así podrá intercambiarlas -e incluso, negociarlas con sus “otros”- a lo largo del tiempo.

De todo lo anterior podemos concluir que las distancias entre la experiencia tal como fue vivida y su relato se relacionan con los siguientes fenómenos:

\footnotetext{
${ }^{19}$ Norbert Elias, La sociedad de los individuos. Ensayos, Barcelona, Península, col. Ideas, 1990.

${ }^{20}$ Juergen Franzke, "El mito de la historia de vida", Historia y Fuente Oral, núm. 2, Barcelona, 1989, pp. 57-64.

${ }^{21}$ Jean-Claude Kaufmann, L'entretien compréhensif, París, Nathan, col. Nathan Université, 1996, pp. 59-60.
} 
1. Los procesos de memorización transforman la experiencia que almacenan.

2. Los procesos de rememoración transforman la experiencia en el momento de traer el recuerdo.

3. Los procesos de socialización se extienden a través de toda la vida, por lo que los individuos nunca están totalmente terminados, siguen sedimentando experiencias y conocimientos durante toda su existencia; motivo por el que, el fenómeno rememorado no sólo cambia debido a los procesos de la memoria, sino también porque el propio individuo cambia con el tiempo, cambia sus propios referentes para interpretar su pasado y su presente. Repiensa la historia en el momento de contarla y la ve de otras maneras porque tiene nuevos referentes.

4. La motivación estética también genera una transformación en la experiencia narrada, que va a asociarse con el criterio estético que tome el narrador.

5. El propio patrón narrativo impone un orden secuencial que reduce el caos de lo experiencial, omite cosas, ordena unos eventos detrás de los otros, a pesar de que muchos ocurrieron en forma simultánea. Este orden secuencial es parte de la búsqueda de volverle inteligible al otro el relato.

6. El sistema interaccional cara a cara (entre entrevistador y narrador) en el que se produce la narración, permite que la transformación también esté en función de quién es el otro para el que se está narrando.

7. Por último, la armonización retrospectiva para presentarse ante los otros como un ser único, también genera otra transformación en la narración experiencial.

Todo lo anterior nos permite plantear que en cualquier relato de vida, desde una doble estructuración:

- Por un lado, se da testimonio de una dimensión social, que toma cuerpo en las prácticas narradas.

- Por otro lado, todo relato tiene también una cara más subjetiva en la que aparece la reconstrucción, el montaje, e incluso la fabulación. Pero estos rasgos no la hacen menos valiosa para comprender la realidad social, puesto que se trata de montaje y ficción construidos dentro de una praxis social, y no en el mundo de la fantasía. 
Podemos concluir que para la investigación en ciencias sociales, los relatos autobiográficos no constituyen un método en el sentido de un camino lógico que busca demostrar la verdad, sino que son testimonios de una existencia inscrita en la historia, con los cuales la persona -sin saberlo ni proponérselo- reconstruye un espacio social mediante el uso del lenguaje y de su memoria. El relato de vida es invención, aunque es una construcción permanente gestada en el marco de la praxis social y no en el mundo de la fantasía. De ahí deriva su valor como expresión de un fragmento de lo social y su potencialidad respecto a la acción futura.

\section{La fabulación de la acción narrada}

Acabamos de ver que la experiencia sufre una distorsión al ser construida como relato, es decir, al ser puesta en el lenguaje. Así, el relato acerca de una (o unas) experiencia(s) no la(s) reproduce exactamente tal como ocurrió, debido al conjunto de procesos intervinientes ya mencionados. En el apartado anterior abordamos los procesos que generan la transformación; en este otro, buscamos ofrecer una interpretación sobre la forma y estructura de ese relato distorsionado respecto a la experiencia.

La distorsión de la experiencia se puede entender como el ejercicio espontáneo y necesario ${ }^{22}$ que efectúa el narrador, con el fin de darle nueva forma a lo experiencial. Este ejercicio no planeado por el hablante, resulta de la introducción de la experiencia relatada en algún conocimiento colectivo que pueda reconocer un vínculo significativo con la propia experiencia. Esto es algo semejante a darle una estructura al relato en función de ese conocimiento colectivo, darle otra forma, pero una que resulte significativa. De alguna manera esto se puede pensar desde la relación hermenéutica entre un texto y su contexto.

Este proceso (o ejercicio) de volver a introducir la experiencia en esta nueva estructura, aparentemente ajena a la experiencia en cuestión, es lo que se conoce como la "fabulación" que logra el narrador en torno a sus vivencias. Aquí, el concepto de fábula remite al relato que incorpora la "imaginación" en las prácticas sociales. La utilidad de considerar que en el relato existe fabulación (como un contexto de sentido) radica en que la fábula es portadora de significados sociales y, por lo tanto, revela un

${ }^{22}$ Es una condición necesaria, dado que lo experiencial tiene la forma (o lo "informe”) de lo vivido, mientras que el relato tiene una forma lingüística. 
medio social, un contexto social de significados. Toda fabulación habla acerca del espacio social en el que ocurre su estructuración, de las relaciones entre los grupos sociales que componen ese espacio social; de los actores y los papeles que juegan. Analíticamente, esto implica pasar de aquel problema que la investigación que busca verdades identifica como "la mentira", al otro más complejo de la "fabulación" como imaginación que interpreta las experiencias y en ese proceso reconstruye la realidad social.

En el caso de los relatos autobiográficos, la fabulación puede asimilarse a una forma de mito, ${ }^{23}$ que en términos metodológicos tiene la gran virtud de abrir claves de interpretación de las narraciones experienciales; aunque es necesario aclarar que no nos referimos a los mitos en términos de relatos míticos, generalmente épicos. La interpretación de los relatos autobiográficos desde los mitos supone tratarlos como estructuras narrativas que le dan sentido a lo vivido. Así, el relato autobiográfico (por medio de los mitos) permite volver a inscribir la experiencia individual en un pasado común que llega al presente por transmisión intergeneracional, $\mathrm{y}$ al que se le reconoce la capacidad de pintar en una imagen alguna parte de la sociedad en que vivimos. Por ello, analíticamente el mito representaría una especie de mediación entre la memoria colectiva que habla del pasado común, y la experiencia individual.

En este contexto, el mito asume el papel de una "metáfora colectiva" que conserva y perpetúa una memoria colectiva, ${ }^{24}$ un pasado común, en sistemas de representaciones factibles de ser narradas, y organizados por códigos simbólicos. ${ }^{25} \mathrm{El}$ mito funciona como una serie de saberes compartidos específicos de una comunidad, de una sociedad. Por ello, el mito le permite al narrador comunicar su experiencia en términos sociales, esto es, como representaciones colectivas (tal y como se condensan en el seno del imaginario y la memoria colectivos). Mediante estos mitos el individuo se puede constituir en un actor social, en sujeto inscrito en la historia. ${ }^{26}$ Los mitos permiten articular el yo con su pasado, aunque también pueden aportar elementos respecto a la articulación del yo con su futuro.

En algunas ocasiones se recurre a mitos de la historia de la comunidad a la que se pertenece, mitos de los grupos de perte-

${ }^{23}$ Didier Vrancken, 1986.

${ }^{24}$ Idem.

${ }^{25}$ Marie-Françoise Chanfrault-Duchet, 1995.

${ }^{26}$ Idem. 
nencia, que hablan de la identidad social. Paralelamente se puede recurrir a mitos de la historia individual, los que usualmente se conocen como mitos fundadores del yo, que dan cuenta de la singularidad de lo vivido. ${ }^{27}$

Algunos autores, como Chanfrault-Duchet, distinguen tres tipos de mitos que movilizan tres niveles de la memoria, y a su vez, remiten a tres campos de la identidad: Son los mitos de la historia del individuo, los de la comunidad y los de la sociedad. Estos tres campos de la identidad y la memoria sobre los que se entreteje la narración, en términos del proceso de descifrar el código al que se enfrenta el investigador, pueden ser vistos como una figura matricial sobre el tipo de relación del individuo con el mundo. Por ejemplo, "el reto", "el afán de superación personal”, bien pueden ser "mitos" sobre los cuales algunos individuos entretejan la narración de su vida. Es por ello que los mitos operan para el investigador como verdaderas plantillas de desciframiento o de interpretación: le dan un sentido socialmente compartido a lo vivido. ${ }^{28}$

El mito siempre opera en el ámbito del lenguaje -facilitándose así su transmisión- como una configuración (una versión) de la realidad, en la que se expresan normas y valores de los grupos sociales que lo sostienen, y por su persistencia a través del tiempo crea la ilusión de ser "una copia" de la realidad. El mito organiza, estructura acontecimientos en función de valores, creencias, concepciones del mundo. Su función es la de rememorar el pasado por medio del recuerdo, y en él, la cultura de los grupos. Así, su memorización asegura su conservación para una ulterior evocación. Pero el mito no sólo configura y perpetúa, también concentra imágenes, episodios de las experiencias de una colectividad. ${ }^{29}$ En última instancia, el mito es otro sistema para explicar nuestra experiencia del mundo, un sistema diferente de los modelos explicativos científico-racionales a los que recurrimos usualmente: "Es una forma más antigua de racionalidad que subyace bajo los sedimentos que depositó la ilustración". ${ }^{30}$

Con todo lo anterior estamos reconociendo que si entre la experiencia tal como fue vivida y su narración experiencial hay una distorsión, ésta se puede leer en algún mito que el narrador recoja. En síntesis, el mito puede ser concebido como una media-

\footnotetext{
${ }^{27}$ Idem.

${ }^{28}$ Idem.

${ }^{29}$ Didier Vrancken, 1986.

${ }^{30}$ Juergen Franzke, 1989.
} 
ción entre la experiencia y su relato. Esas transfiguraciones o distorsiones no permiten calificar al relato como más falso o verdadero. Simplemente el relato recurre a un sistema particular (el mito) con el que el individuo da testimonio de la experiencia en el mundo, al tiempo que la inscribe en un mundo al que reconoce pertenencia.

De esta manera para el investigador, descifrar el mito que estructura una narración autobiográfica técnicamente significa hallar una clave de interpretación del texto; aunque, metodológicamente, implica descifrar los contornos de un sistema de significación al que ha recurrido el narrador, ${ }^{31}$ y dentro de los cuales se conforman las intencionalidades de las acciones sociales en cuestión. No obstante, las palabras del narrador y la estructura narrativa que sigue (de acuerdo con algún mito) sólo adquieren todo su sentido a condición de que sean interpretadas con referencia a los distintos grupos sociales de los cuales el actor (el personaje de la narración) da cuenta a lo largo de su existencia: familia, escuela, asociaciones, y no simplemente los grupos en los que hoy está inserto, sino también en los que ha estado en otros momentos de su vida.

En síntesis, la narración autobiográfica nos enfrenta con el desafío de encontrar esos mitos que constituyen verdaderos mecanismos de construcción de la realidad social, en tanto delimitadores de contornos de sistemas de significación. De tal modo que la narración nos abre al conocimiento de los sistemas de significación que construyen el mundo orientando las acciones sociales. El procesamiento de experiencias pasadas para construir un relato sobre ellas, es un procesamiento preestructurador de las percepciones futuras. En última instancia, no se puede disociar la representación, la práctica y el discurso; constituyen un todo. ${ }^{32}$ En esta perspectiva, la narración autobiográfica es constitutiva de la acción futura y, en consecuencia, de la realidad social.

\section{Bibliografía}

Berger, Peter y Thomas Luckmann (1997), Modernidad, pluralismo y crisis de sentido. La orientación del hombre moderno, Barcelona, Paidós.

${ }^{31}$ Chanfrault-Duchet, 1995.

${ }^{32}$ Didier Martin y Philippe Royer-Rastoll, Répresentations sociales et pratiques quotidiennes, París, L'Harmattan, 1990, p. 196. 
Cabanes, Robert (1996), "El enfoque biográfico en sociología”, Cuadernos del CIDS, serie II, núm. 1, julio, Bogotá.

Crespi, Franco (1997), Acontecimiento y estructura. Por una teoría del cambio social, Buenos Aires, Nueva Visión.

Chanfrault-Duchet, Marie-Françoise (1987), "¿Le récit de vie: donnée ou texte?", Cahiers de Recherche Sociologique, vol. 5, núm. 2, otoño, Montreal, pp. 11-28.

— (1995), "Mitos y estructuras narrativas en la historia de vida: la expresión de las relaciones sociales en el medio rural", Historia y Fuente Oral, núm. 9, Barcelona, pp. 12-21.

Elias, Norbert (1990), La sociedad de los individuos. Ensayos, Barcelona, Península, col. Ideas.

Franzke, Juergen (1989), "El mito de la historia de vida", Historia y Fuente Oral, núm. 2, Barcelona, pp. 57-64.

Freund, Julien (1986), Sociología de Max Weber, Barcelona, Península, col. Homo Sociologicus.

Geertz, Clifford (1996), La interpretación de las culturas, Barcelona, Gedisa, col. Antropología.

Giddens, Anthony (1997), Modernidad e identidad del yo. El yo y la sociedad en la época contemporánea, Barcelona, Península.

Kaufmann, Jean-Claude (1994), "Rôles et identité: l'exemple de l'entrée en couple", Cahiers Internationaux de Sociologie, vol. XCVII, París, PUF.

— (1996), L'entretien compréhensif, París, Nathan, col. Nathan Université.

León, Emma y Hugo Zemelman (1997), “Presentación”, en Emma León y Hugo Zemelman (coords.), Subjetividad: umbrales del pensamiento social, Barcelona, Anthropos-CRIMCoordinación de Humanidades, col. Ciencias Sociales. 
Luckmann, Thomas (1996), Teoría de la acción social, Barcelona, Paidós.

Martin, Didier y Philippe Royer-Rastoll (1990), Répresentations sociales et pratiques quotidiennes, París, L'Harmattan.

Piña, Carlos (1989), "Sobre la naturaleza del discurso autobiográfico”, Argumentos, núm. 7, agosto, México, UAM-Xochimilco, pp. 131-160.

Vrancken, Didier (1986), "Memoire de chapeliers: du récit à l'élaboration du mythe", Cahiers Internationaux de Sociologie, julio-diciembre, año 33, vol. 81, pp. 315-324.

Zemelman, Hugo (1994), "Sobre la importancia de las realidades que se ocultan", Tramas, Subjetividad y Procesos Sociales, núm 6: Sujeto y Subjetividad, UAM-Xochimilco, pp. 9-20.

— (1997), "Sujetos y subjetividad en la construcción metodológica”, en Emma León y Hugo Zemelman (coords.), Subjetividad: umbrales del pensamiento social, Barcelona, Anthropos-CRIM-Coordinación de Humanidades, col. Ciencias Sociales. 